\title{
Trial Disease Maximum Time Allowed in Planned Assessment Interval
}

National Cancer Institute

\section{Source}

National Cancer Institute. Trial Disease Maximum Time Allowed in Planned Assessment

Interval. NCI Thesaurus. Code C117705.

The upper limit in time of a planned period of time between planned trial disease assessments. 